A.C $\begin{aligned} & \text { Revista de } \\ & \text { Administração } \\ & \text { Contemporânea } \\ & \text { Journal of Contemporary Administration }\end{aligned}$

\title{
Ciclos Políticos e Gestão Fiscal nos Municípios Brasileiros
}

Political Cycles and Fiscal Management in Brazilian Municipalities

\author{
Alann Inaldo Silva de Sá Bartoluzzio ${ }^{\circledR}$ \\ Luiz Carlos Marques dos Anjos ${ }^{1}$
}

\section{RESUMO}

O estudo analisou como incentivos político-eleitoreiros influenciam a gestão fiscal dos municípios brasileiros e seus desdobramentos nos resultados eleitorais. Nas estimações realizadas dois achados se sobressaem. O primeiro é que apesar de existir um aumento nos investimentos, visíveis à população e associados pela literatura a resultados eleitorais favoráveis, os partidos reconduzidos também possuem uma estrutura de pessoal mais sustentável e melhores condições de liquidez no curto prazo, com desempenhos alavancados em períodos estratégicos, como em anos eleitorais. $\mathrm{O}$ segundo é que, apesar dos partidos com recondução sinalizarem melhores níveis na condição fiscal nos três ciclos políticos, no período pós-eleitoral as médias se retraem para patamares inferiores ao alcançado pela gestão no início do primeiro mandato. Portanto, embora indiquem melhores condições fiscais em anos eleitorais, o efeito da sinalização se inverte no ano seguinte. Como o impacto das decisões da gestão não estará disponível para o eleitorado imediatamente no período eleitoral, os políticos podem utilizar de estratégias fiscais para evitar que o equilíbrio fiscal seja prejudicado nos momentos estratégicos e postergar o desembolso para o ano pós-eleitoral, decisão que não prejudicaria a gestão fiscal atual e o recebimento de votos.

Palavras-chave: teoria dos ciclos políticos, finanças municipais, gestão fiscal.

JEL Code: E62, D73, D72.

\footnotetext{
' Universidade Federal de Pernambuco, Centro de Ciências Sociais Aplicadas, Departamento de Ciências Sociais e Atuariais, Recife, Pernambuco, Brasil.
}

Como citar: Bartoluzzio, A. I. S. de S., \& Anjos, L. C. M. dos (2020). Ciclos políticos e gestão fiscal nos municípios brasileiros. Revista de Administração Contemporânea, 24(2), 167-180. https://doi.org/10.1590/1982-7849rac2020190190

Editor-chefe: Wesley Mendes-Da-Silva Recebido em: 27/05/2019 Última versão recebida em: 06/09/2019 Aceito em: 27/09/2019

\begin{tabular}{|c|c|c|c|c|c|c|c|c|c|}
\hline & 1 & 2 & 3 & 4 & 5 & 6 & 7 & 8 & 9 \\
\hline $1^{a}$ rodada & (x) & p & $\stackrel{8}{2}$ & & & & & & \\
\hline $2^{a}$ rodada & 2 & (x) & & & & & & & \\
\hline
\end{tabular}




\section{INTRODUÇÃO}

Como incentivos político-eleitoreiros influenciam a gestão fiscal dos municípios brasileiros e quais seus desdobramentosnos resultados eleitorais? Essa se mostra uma questão pertinente ao levarmos em consideração a discussão proposta por Downs (1957) sobre a possibilidade de que, em um sistema democrático, os políticos, os invés de formularem projetos com o intuito de atingir sua função social, os façam visando ampliar o número de votos que irão receber, negligenciando as demandas sociais em prol das motivações privadas para alcançar renda, prestígio e poder.

A literatura sobre ciclos políticos demonstra que a gestão fiscal pode ser manipulada para fins eleitoreiros de pelo menos duas formas. A princípio pelo aumento da despesa pública em momentos estratégicos visando a sinalização de competência aos eleitores (Block, 2002; Shi \& Svensson, 2006; Veiga \& Veiga, 2007a; Klein, 2010). Em seguida, pela manipulação na composição da despesa pública para as categorias valorizadas pelos votantes, pois os políticos buscam demonstrar que compartilham das mesmas prioridades fiscais dos cidadãos (Eslava, 2005; Veiga, \& Veiga, 2007a; Sakurai \& Menezes, 2008; Vergne, 2009, Drazen \& Eslava, 2010; Queiroz, 2015; Klein \& Sakurai, 2015). Portanto, a estrutura fiscal é uma ferramenta que pode ser utilizada para o alcance de incentivos político-eleitoreiros, como teoriza Downs (1957).

Análises desenvolvidas sobre a condição fiscal das instituições locais no Brasil indicam baixa aderência aos instrumentos e dispositivos legais que versam sobre a responsabilidade com as contas públicas. A avaliação divulgada por meio do Índice Firjan de Gestão Fiscal (IFGF) para o ano de 2016 demonstra que dos 4.544 municípios analisados, cerca de $85,9 \%$ apresentaram situação fiscal difícil ou crítica, sendo observado para esse período o maior percentual de prefeituras classificadas como em dificuldade fiscal desde o início da série histórica em 2006 (Sistema FIRJAN, 2017).

Levando em consideração os problemas enfrentados pelos governos subnacionais e visando responder à questão acima, buscamos compreender como a gestão fiscal dos municípios pode estar subordinada aos incentivos políticos utilizando indicadores fiscais que permitem uma avaliação mais específica do que os déficits orçamentários comumente abordados na literatura. Essas informações abrangem um conjunto de indicadores contábeis com potencial relação aos ciclos políticos e os componentes do IFGF.

Dividido em duas etapas, o estudo explora a perspectiva política sobre a gestão fiscal em períodos estratégicos e com potencial relação aos ciclos políticos para verificar se a condição fiscal está sendo influenciada por questões político-eleitoreiras. Já a avaliação dos resultados eleitorais foi realizada a partir de dois aspectos principais, o primeiro com base na assimetria temporária de informações entre governantes e eleitores sobre a política fiscal; e o segundo sobre como os resultados eleitorais podem estar relacionados ao negligenciamento político para essas questões.

Ressalta-se que, a partir da utilização de informações abrangentes da gestão fiscal, é possível desenvolver resultados mais detalhados sobre a manipulação política se comparados aos achados observados com base nos déficits orçamentários ou na expansão da despesa pública, o que contribui com as discussões nacionais e internacionais sobre o tema (Block, 2002; Shi \& Svensson, 2006; Veiga \& Veiga, 2007a; Klein, 2010; Klein \& Sakurai, 2015). Além disso, até o presente momento, não foram observados estudos nacionais que englobem três ciclos políticos na análise da condição fiscal a nível municipal, o que permite o desenvolvimento de avaliações consistentes para o tópico proposto.

Observamos que apesar de existir um aumento nos investimentos em períodos estratégicos nos municípios onde os partidos foram reconduzidos, essas regiões possuem também melhores condições fiscais de maneira geral. No entanto, o efeito da sinalização se inverte no período pós-eleitoral, indicando um desgaste fiscal imediatamente após as eleições, um resultado compatível com a assimetria da informação sinalizada nos Ciclos Político-Orçamentários. Portanto, um convite para pensar a condição fiscal para além de uma questão meramente técnica, o que pode auxiliar no processo de fiscalização dessas instituições e no desenvolvimento de normativos sobre o tema.

\section{FUNDAMENTAÇÃO TEÓRICA}

\section{Teoria dos ciclos políticos}

As discussões teóricas sobre ciclos políticos surgiram de estudos iniciais que observaram como as democracias eram submetidas a recessões econômicas incentivadas por líderes empresariais como medida disciplinar (Kalecki, 1943). Além da avaliação de uma forte relação entre períodos de prosperidade e crises econômicas com os resultados eleitorais (Akerman, 1947).

Esses estudos servem como ponto de partida para compreender o trabalho de Downs (1957), que propôs uma teoria econômica da democracia para explicar como os eleitores escolhem seus representantes e como os governos tomam decisões em um regime democrático. Para o autor, os partidos políticos em um sistema democrático, ao invés de formularem políticas com objetivo de atingir sua função social, buscam realizar políticas estritamente com a finalidade de maximizar o número de votos que podem receber. 
Downs (1957) contribuiu para o desenvolvimento de uma teoria subjacente sobre ciclos políticos ao indicar como aspectos do conhecimento imperfeito influenciam as decisões governamentais. As pesquisas foram desenvolvidas essencialmente a partir das hipóteses de racionalidade e irracionalidade dos eleitores e pelas perspectivas oportunista e ideológica.

Partindo dessas contribuições iniciais, Nordhaus (1975) explorou a manipulação de variáveis macroeconômicas para fins eleitorais. A ideia central do seu modelo é a de que os governantes gerenciam a política fiscal e monetária com o objetivo de gerar um cenário econômico favorável aos eleitores em períodos que antecedem as eleições, resultando no denominado Political Business Cycle ou Ciclos Político-Econômicos.

Nesse cenário, a política econômica é manipulada de forma que a taxa de desemprego declina em períodos antecedentes às eleições. Logo após o período eleitoral, existe um aumento na taxa de desemprego com o objetivo de diminuir os níveis de inflação. Quando novas eleições se aproximam o ciclo se repete, refletindo positivamente no eleitorado que reage, por sua vez, de forma míope à política do governo e supervaloriza as ações de curto prazo (Nordhaus, 1975).

Introduzindo o viés ideológico para explicar o funcionamento do ciclo político-partidário, uma perspectiva diferente daindicada por Nordhaus(1975), o estudo de Hibbs (1977) demonstra que os partidos políticos priorizarão as políticas macroeconômicas de acordo com os interesses econômicos e preferências do grupo social representado. Isso significa que, enquanto os partidos de direita são mais favoráveis a uma política de controle fiscal mais arrojada para evitar flutuações nas taxas de inflação, os partidos de esquerda são mais inclinados a uma política distributiva para diminuir as taxas de desemprego.

Em uma concepção similar à de Hibbs (1977), o estudo de Alesina (1987) parte de duas modelagens distintas para o entendimento de questões partidárias nos ciclos político-econômicos. A principal delas é a de que as partes possuem preferências e prioridades intrínsecas na sua política econômica, pois cada partido político representará os interesses de um eleitorado distinto. Se existem dúvidas sobre as preferências dos eleitores, cada um formulará sua plataforma política com diferentes funções e objetivos para representar grupos específicos, entendendo-se que os partidos se importam com os efeitos da sua política e que o eleitorado possui diferentes incentivos (Alesina, 1987).

Durante as décadas de 1970 e 1980 estudos passaram a ser desenvolvidos considerando que os eleitores são agentes racionais e possuem conhecimento sobre a política econômica. Essas pesquisas abrangem os Modelos Racionais Partidários, com as contribuições de Alesina (1987) e os Modelos Racionais Oportunistas, abordados inicialmente com os estudos de Rogoff e Sibert (1988) e Rogoff (1990).

Ainda com base nas suposições básicas dos modelos clássicos, Rogoff e Sibert (1988) discorrem que os eleitores possuem expectativas racionais. Nessa perspectiva, os governos seriam avaliados pelo nível de competência, indicado pela capacidade de fornecer um determinado nível de serviços governamentais com o menor número de receitas, pois os eleitores são favoráveis aos governos mais eficientes.

Mais tarde, ao desenvolver um modelo multidimensional de sinalização, Rogoff (1990) considera que tanto os eleitores como os políticos são agentes racionais e buscam maximizar sua utilidade. Nesse sentido, os ciclos surgem a partir de uma assimetria de informação temporária sobre a competência dos incumbentes na produção de bens públicos e a sinalização do desempenho ocorre a partir da manipulação de variáveis orçamentárias, como impostos, transferências governamentais e gastos de consumo do governo.

\section{Ciclos políticos e gestão fiscal}

Entre as ferramentas disponíveis e passíveis de influência política está a gestão fiscal. O estudo desenvolvido por Brender e Drazen (2003) indica que a manipulação da política fiscal é um fenômeno atribuído às novas democracias, sendo mais provável de vivenciarem os ciclos políticos pela dificuldade de avaliação e de processamento das informações pelos eleitores, além de serem menos experientes com o sistema eleitoral e, por isso, estão mais expostos à manipulação fiscal. No entanto, sua ocorrência não é exclusiva das novas democracias, mesmo sendo mais provável vivenciarem nessas regiões (Streb, Lema \& Torrens, 2009; Veiga \& Veiga, 2007b; Klomp \& Haan, 2013).

Essa manipulação pode acontecer pelo acréscimo no consumo do governo em períodos eleitorais ou pela alteração na composição dos gastos públicos. O aumento da despesa pública em momentos estratégicos, como demonstra Block (2002), Shi e Svensson (2006) e Veiga e Veiga (2007a), pode acontecer pelo incentivo que os políticos possuem na sinalização de competência nos períodos eleitorais. Isso significa que, com a expansão da despesa em áreas finalísticas nos períodos estratégicos, os eleitores podem tomar decisões que são favoráveis ao titular com base no volume de bens fornecidos e só tomarem conhecimento das consequências fiscais em um período subsequente. 
Em relação à alteração na composição dos gastos públicos, isso ocorre porque os eleitores são simpáticos a determinados gastos e os políticos podem direcionar as despesas para essas categorias visando demonstrar que compartilham das mesmas preferências dos cidadãos e, assim, aumentar as chances de reeleição (Drazen \& Eslava, 2010). Esse aumento acontece especialmente nas despesas com investimentos associados a projetos de infraestrutura visíveis à população (Eslava, 2005; Veiga \& Veiga, 2007a; Vergne, 2009; Queiroz, 2015). No entanto, essas alterações não são acompanhadas necessariamente de uma deterioração na condição fiscal das instituições.

Isso porque a manipulação desenfreada na composição da despesa pública pode refletir negativamente nas eleições dado o conservadorismo fiscal e o nível de informação dos eleitores (Peltzman, 1992). Nesse sentido, o apoio só acontece quando a estrutura dos gastos não prejudica o desempenho fiscal dos municípios (Drazen \& Eslava, 2005). Por isso, os políticos vão mudar a composição para as áreas mais visíveis, mas evitarão déficits globais em função do impacto negativo que estes exercem nos resultados eleitorais (Eslava, 2005; Vergne, 2009; Drazen \& Eslava, 2005; Brender \& Drazen, 2008).

Além do conservadorismo dos eleitores, Rose (2006) argumenta que o contexto institucional no qual os orçamentos são desenvolvidos influencia o entendimento da manipulação fiscal. Portanto, maiores restrições sobre o oportunismo político e o estabelecimento de regras mais arrojadas diminuem a ocorrência de déficits por motivação política (Rose, 2006). Esse resultado é reforçado por Eslava (2011), que aponta a transparência orçamentária, centralização do processo orçamentário e a determinação de limites para os déficits fiscais como questões importantes para o entendimento do equilíbrio fiscal das instituições.

No contexto brasileiro, as contribuições não se distanciam dos achados no âmbito internacional. Isso porque aumentos nos gastos públicos em períodos eleitorais foram observados e estavam positivamente associados às chances de reeleição dos políticos (Sakurai, 2005; Sakurai \& Menezes, 2011; Arvate, Mendes, \& Rocha, 2010; Klein, 2010), desde que dentro dos limites de déficits aceitos pelos eleitores (Klein, 2010). Outra possibilidade seria a manipulação na composição da despesa pública para áreas específicas, que pode acontecer sem necessariamente prejudicar o equilíbrio fiscal das instituições (Sakurai \& Menezes, 2008; Klein \& Sakurai, 2015; Queiroz, 2015).

\section{PROCEDIMENTOS METODOLÓGICOS}

\section{Definição da amostra}

Para seleção da amostra utilizou-se uma Amostragem Estratificada Proporcional. Os municípios foram divididos em sete estratos. A partir dessa divisão foi possível observar a quantidade de observações que compõe cada grupo e, posteriormente, o percentual a ser analisado considerando um Erro Amostral de 5\% e um Grau de Confiança de 95\%, totalizando 360 gestões. Os estratos e o percentual de municípios podem ser observados na Tabela 1 .

Tabela 1. Seleção dos Municípios que Compõem a Amostra.

\begin{tabular}{|c|c|c|c|c|c|}
\hline Estratos & Habitantes & $\begin{array}{l}\text { Quantidade de } \\
\text { Municípios }\end{array}$ & Amostragem & Margem & $\begin{array}{l}\text { Municípios } \\
\text { Analisados }\end{array}$ \\
\hline I & $>1 \leq 5.000$ & 1.235 & 80 & 9 & 89 \\
\hline II & $>5.000 \leq 10.000$ & 1.215 & 78 & 12 & 90 \\
\hline III & $>10.000 \leq 20.000$ & 1.352 & 87 & 13 & 100 \\
\hline IV & $>20.000 \leq 50.000$ & 1.103 & 71 & 14 & 85 \\
\hline $\mathrm{V}$ & $>50.000 \leq 100.000$ & 355 & 23 & 7 & 30 \\
\hline VI & $>100.000 \leq 500.000$ & 268 & 18 & 7 & 25 \\
\hline \multirow[t]{2}{*}{ VII } & $>500.000$ & 42 & 3 & 3 & 6 \\
\hline & Total & 5.570 & 360 & 65 & 425 \\
\hline
\end{tabular}

Nota. Seleção dos municípios que compõem a amostra a partir de uma amostragem estratificada proporcional, considerando um erro amostral de 5\% e um grau de confiança de $95 \%$. Em cada estrato foi adicionada uma margem abrangendo cerca de $7 \%$ a $9 \%$ da população, somando 425 municípios. 
$\mathrm{Na}$ prevenção de possíveis problemas decorrentes da ausência ou indisponibilidade de dados, foi adicionada uma margem em relação ao percentual inicial $(6,46 \%)$, aumentando a seleção de municípios em cada estrato para valores entre $7 \%$ e $9 \%$ da população. Dessa forma, as análises subsequentes serão desenvolvidas considerando informações disponíveis para 425 gestões locais.

\section{Mensuração dos ciclos políticos}

O ciclo político é o mandato eleitoral destacado entre os anos com eleições municipais (2004, 2008, 2012 e 2016). As eleições servem como base para mensuração das variáveis políticas, utilizadas para analisar a influência que exerceram na condição fiscal dos municípios entre 2006 a 2016 (três ciclos políticos), períodos com dados disponíveis para o IFGF e divulgados pelo Sistema da Federação das Indústrias do Estado do Rio de Janeiro (Firjan).

\section{Gestão fiscal dos municípios}

\section{Índice Firjan de gestão fiscal}

O IFGF é um índice construído a partir de cinco indicadores com potencial de explicar a gestão fiscal dos municípios. Os quatro primeiros possuem peso de $22,5 \%$ sobre o IFGF total, enquanto o Custo da Dívida soma $10 \%$ da nota. Um menor peso é atribuído a esse item em virtude do baixo grau de endividamento dos municípios brasileiros, seja pela incapacidade de contraírem dívidas ou pelas diversas restrições legais às quais estão sujeitos (Sistema FIRJAN, 2017).

Tabela 2. Itens que compõem o Índice Firjan de Gestão Fiscal.

\begin{tabular}{cc}
\hline Indicador & Fórmula \\
\hline $\begin{array}{c}\text { Receita } \\
\text { Própria }\end{array}$ & Receita Própria / Receita Corrente Líquida \\
$\begin{array}{c}\text { Gastos com } \\
\text { Pessoal }\end{array}$ & Gasto com Pessoal / Receita Corrente \\
Líquida \\
$\begin{array}{c}\text { Investimentos } \\
\text { Liquidez }\end{array}$ & $\begin{array}{c}\text { Investimentos / Receita Corrente Líquida } \\
\text { (Caixa - Obrigações em Circulação) / Receita } \\
\text { Corrente Líquida }\end{array}$ \\
$\begin{array}{c}\text { Custo da } \\
\text { Dívida }\end{array}$ & Juros e Amortizações / Receita Líquida Real \\
\hline
\end{tabular}

Nota. Indicadores utilizados para a mensuração da condição fiscal dos municípios de forma abrangente (IFGF Geral). Após o cálculo dos itens, a qualidade fiscal das gestões é distribuída em um intervalo que vai de 0 (mínimo) a 1 (máximo). Fonte: Adaptado de: Sistema FIRJAN. (2017, August). Índice Firjan de Gestão Fiscal [IFGF]: recorte municipal (abrangência nacional), ano base 2013. Retrieved from http://www.firjan.com.br/ifgf/ consulta-ao-indice/
Após o cálculo do IFGF uma pontuação é atribuída a cada município. De maneira geral, o indicador e seus componentes variam de 0 (mínimo) a 1 (máximo), sendo considerado que, quanto mais próximo a um, melhor a gestão fiscal. Esse intervalo é divido em conceitos de referência para facilitar a análise, a saber: Conceito A (Gestão de Excelência: $>0,8$ pontos), B (Boa Gestão: $\geq 0,6 \leq 0,8$ pontos), C (Gestão em Dificuldade: $\geq 0,4 \leq 0,6$ pontos) e D (Gestão Crítica: $\leq 0,4$ pontos).

\section{Indicadores contábeis do setor público}

A perspectiva contábil foi analisada com base no estudo de Vicente e Nascimento (2012), que propôs uma discussão relacionada ao que denominam como "Ciclos Político-Contábeis", incluindo informações financeiras, patrimoniais e orçamentárias das entidades do setor público.

\begin{tabular}{|c|c|}
\hline \multicolumn{2}{|c|}{ Indicadores } \\
\hline $\begin{array}{c}\text { Saldo de restos a pagar não } \\
\text { processados em relação às } \\
\text { despesas totais }\end{array}$ & $\begin{array}{c}\text { Quociente do resultado } \\
\text { orçamentário corrente }\end{array}$ \\
\hline $\begin{array}{c}\text { Saldo de restos a pagar } \\
\text { processados em relação às } \\
\text { despesas totais }\end{array}$ & $\begin{array}{c}\text { Representatividade das } \\
\text { transferências voluntárias } \\
\text { recebidas da União }\end{array}$ \\
\hline $\begin{array}{c}\text { Quociente do resultado } \\
\text { orçamentário }\end{array}$ & $\begin{array}{c}\text { Representatividade das } \\
\text { transferências voluntárias } \\
\text { recebidas dos Estados }\end{array}$ \\
\hline $\begin{array}{c}\text { Quociente de geração/Consumo } \\
\text { de caixa no exercício }\end{array}$ & $\begin{array}{c}\text { Representatividade das receitas } \\
\text { tributárias }\end{array}$ \\
\hline $\begin{array}{c}\text { Quociente do resultado } \\
\text { financeiro apurado no balanço } \\
\text { patrimonial }\end{array}$ & $\begin{array}{c}\text { Representatividade das despesas } \\
\text { de pessoal }\end{array}$ \\
\hline $\begin{array}{c}\text { Arrecadação da receita de dívida } \\
\text { ativa em relação ao saldo da } \\
\text { dívida ativa }\end{array}$ & $\begin{array}{c}\text { Representatividade das despesas } \\
\text { com investimentos }\end{array}$ \\
\hline $\begin{array}{c}\text { Índice de endividamento do ente } \\
\text { federativo }\end{array}$ & \\
\hline
\end{tabular}

Figura 1. Indicadores para Avaliação da Gestão Fiscal na perspectiva dos Ciclos Político-Contábeis.

Indicadores contábeis com potencial de explicar a condição fiscal dos municípios em uma perspectiva alinhada aos Ciclos Político-Contábeis. Fonte: Adaptado de Vicente, E. F. R., \& Nascimento, L. S. (2012). A efetividade dos ciclos políticos nos municípios brasileiros: Um enfoque contábil. Revista de Contabilidade e Organizações, 6(14), 106-126. https://doi.org/10.11606/rco.v6i14.45402

Ressalta-se que pela indisponibilidade e inconsistência das informações contábeis divulgadas pelo Sistema de Informações Contábeis e Fiscais do Setor Público Brasileiro (Siconfi) para o ano de 2016 (Siconfi, n.d.), a análise da gestão fiscal dos municípios por meio dos indicadores contábeis foi desenvolvida considerando apenas os anos de 2008 e 2012, disponibilizadas na plataforma da Secretaria do Tesouro Nacional (STN, n.d.). 
Avaliações e modelos econométricos

Os modelos econométricos foram desenvolvidos em três perspectivas que se complementam: (a) a avaliação de indicadores contábeis com capacidade de explicar a gestão fiscal dos municípios; (b) a perspectiva política sobre a gestão fiscal e (c) a avaliação dos resultados eleitorais.

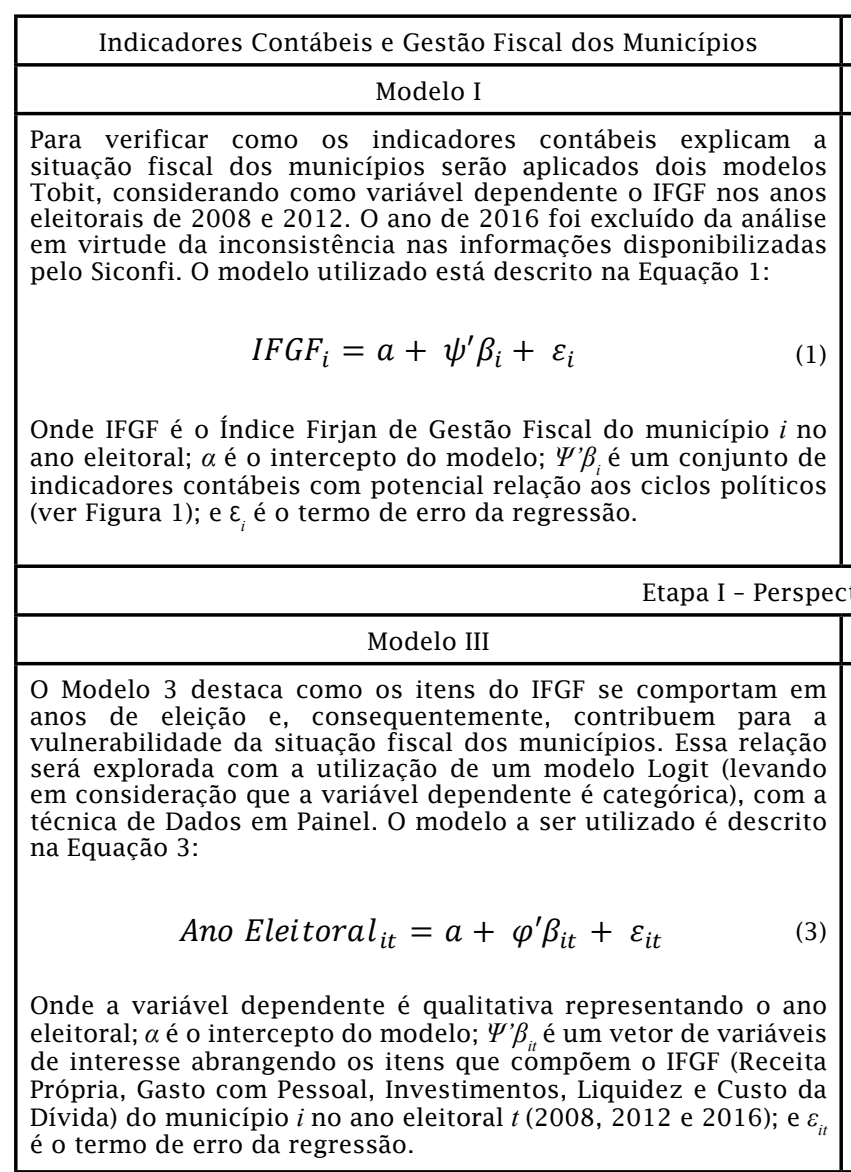

Etapa I - Perspectiva Política sobre a Gestão Fiscal

Modelo II

O Modelo 2 busca verificar como incentivos políticos explicam a gestão fiscal a nível municipal. Para sua execução será utilizado um modelo Tobit (levando em consideração que o índice de gestão fiscal está limitado a um intervalo entre 0 e 1), com a técnica de Dados em Painel:

$$
I F G F_{i t}=a+\omega^{\prime} \beta_{i t}+\varepsilon_{i t}
$$

Onde IFGF é o Índice Firjan de Gestão Fiscal do município $i$ no ciclo político $t$; $\alpha$ é o intercepto do modelo; $\Psi^{\prime} \beta_{i t}$ é um vetor de variáveis de interesse representando aspectos políticos da gestão litocal (mudança de gestor, mandato eleitoral [primeiro e segundo mandatol e ano eleitoral), mensurado por meio de variáveis binárias; e $\varepsilon$ é o termo de erro da regressão, possibilitando verificar como motivações políticas atreladas ao calendário eleitoral e aos tipos de gestão influenciam a situação fiscal dos municípios.

tiva Política sobre a Gestão Fiscal

\begin{tabular}{|c|}
\hline \\
\hline $\begin{array}{l}\text { O Modelo } 4 \text { abrange aspectos da competição política, ideológicos e de controle. } \\
\text { Seu objetivo é observar como a gestão fiscal dos municípios se comporta diante da } \\
\text { competitividade eleitoral e como as diferenças ideológicas se relacionam com as } \\
\text { questões fiscais a nível local: }\end{array}$ \\
\hline$I F G F_{m i}=a+\delta^{\prime} \beta_{i t-1}+\gamma^{\prime} \beta_{i t-1}+\vartheta \beta_{i}+\varepsilon_{i}$ \\
\hline $\begin{array}{l}\text { Onde o IFGFm compreende o valor médio do IFGF para os quatro anos de cada ciclo } \\
\text { político (2008, } 2012 \text { e } 2016) ; \alpha \text { é o intercepto do modelo; } \delta \beta_{i t-l} \text { são duas variáveis } \\
\text { sobre a competição política do município: a quantidade de partidos disputando } \\
\text { as eleições e o percentual de votos a favor do prefeito vencedor. A perspectiva } \\
\text { ideológica é representada por } \gamma^{\prime} \beta_{i t-l^{\prime}} \text { indicando se o partido do prefeito é de } \\
\text { Esquerda, Centro, Direita ou compó outros", de acordo com o critério de } \\
\text { classificação proposto por Speck, Braga e Costa (2015). Por fim, } \vartheta \beta_{i} \text { representa uma } \\
\text { variável dummy para os anos entre } 2012 \text { e } 2016 \text { em decorrência da implementação } \\
\text { da Lei de Acesso à Informação e } \varepsilon_{i t} \text { é o termo de erro da regressão. }\end{array}$ \\
\hline
\end{tabular}

Etapa II - Avaliação dos Resultados Eleitorais

\begin{tabular}{|l|l} 
Modelo V & Modelo VI
\end{tabular}

O Modelo 5 indica como a recondução dos partidos políticos está sendo influenciada pelos itens que compõem o IFGF municipal em anos eleitorais. Para isso, foi mensurado um modelo Logit (atribuindo-se 1 para os municípios com partidos reconduzidos e 0 para os demais) com a técnica de Dados em Painel:

$$
\text { Recondução } o_{i t}=a+\varphi^{\prime} \beta_{i t}+\varepsilon_{i t}
$$

Onde a variável dependente indica a recondução dos partidos políticos nos anos eleitorais (2008, 2012 e 2016); $\alpha$ é o intercepto do modelo; $\Psi^{\prime} \beta_{\text {it }}$ é um vetor de variáveis de interesse incluindo cada um dos cinco itens que formam o IFGF (Receita Própria, Gasto com Pessoal, Investimentos, Liquidez e Custo da Dívida); e $\varepsilon_{i t}$ é o termo de erro da regressão.

O Modelo 6 permite compreender como a gestão fiscal se comporta durante os ciclos políticos de forma mais abrangente. Dada a provável multicolinearidade entre as variáveis, em virtude do IFGF Geral variar pouco durante os anos, os dados foram divididos em dois grupos (um com os partidos reconduzidos e um para os que não houve recondução). Dentro de cada grupo considerou-se como variável dependente a qualidade da gestão fiscal dos municípios e como independente um conjunto de variáveis dummies representando cada um dos anos do ciclo político mais o período pós-eleitoral, sendo estimados modelos Tobit com a técnica de Dados em Painel:

$$
I F G F_{i t}=a+\tau^{\prime} \beta_{i t}+\varepsilon_{i t}
$$

Em que a variável dependente expressa a qualidade da gestão fiscal do município $i$ em cada ciclo político mais o ano pós-eleitoral; $\alpha$ é o intercepto do modelo; $\tau$ ' $\beta_{i t}$ representa um conjunto de variáveis dummies para os ciclos políticos e o ano póseleitoral (2006-2009 para o ciclo que se encerra em 2008; 2010-2013 para o ciclo findo em 2012; e 2014-2016 para o ciclo que antecede o ano eleitoral de 2016); e $\varepsilon_{i t}$ é o termo de erro da regressão.

Figura 2. Desenvolvimento Econométrico do Trabalho.

Modelos econométricos utilizados para alcançar o objetivo do estudo. Abrangem uma avaliação dos indicadores contábeis com potencial de explicar a gestão fiscal dos municípios; a influência política sobre a condição fiscal; e seus desdobramentos eleitorais. Fonte: Elaboração própria. 
Em cada modelo foi verificada a existência de multicolinearidade entre as variáveis por meio do Variance Inflation Factor (VIF) e a hipótese de nulidade dos parâmetros analisada por meio do teste da Razão de Verossimilhança (LV Statistic). Nos modelos com Dados em Painel utilizou-se o teste Hausman para seleção de efeito, recomendando-se a utilização de Efeitos Fixos no Modelo 3 (Tabela 5) e Efeitos Aleatórios no Modelo 5 (Tabela 7). Os modelos Tobit com Dados em Painel (Modelos 2 e 6 ), que constam nas Tabelas 4 e 8 , foram estimados com Efeitos Aleatórios, levando em consideração as inconsistências apontadas por Cameron e Trivedi
(2005) para a estimação de modelos Tobit em painéis menores com Efeitos Fixos.

\section{ANÁLISE DOS RESULTADOS}

\section{Indicadores contábeis e situação fiscal}

A Tabela 3 apresenta as estimativas da relação entre os indicadores oriundos dos subsistemas contábeis (patrimonial, orçamentário e financeiro), com a gestão fiscal dos municípios brasileiros utilizando como parâmetro o IFGF nos anos eleitorais de 2008 e 2012.

Tabela 3. Relação entre Indicadores Contábeis e Situação Fiscal dos Municípios.

\begin{tabular}{|c|c|c|c|c|c|}
\hline \multicolumn{4}{|c|}{ Eleições } & \multicolumn{2}{|c|}{ Eleições } \\
\hline Variáveis & 2008 & 2012 & Variáveis & 2008 & 2012 \\
\hline Restos a Pagar Processados & $0,343 * * *$ & $-0,158$ & Resultado Orçamentário Corrente & $-0,063$ & $-0,009$ \\
\hline Restos a Pagar Não Processados & $-0,281 * * *$ & $-0,393 * * *$ & Transferências Voluntárias (União) & $-0,494 *$ & 0,017 \\
\hline Resultado Orçamentário & $0,387 * * *$ & $0,557 * * *$ & Transferências Voluntárias (Estados) & 0,118 & $-0,010$ \\
\hline Geração de Caixa & $0,000 *$ & $0,000 * * *$ & Receitas Tributárias & $0,689 * * *$ & $0,668 * * *$ \\
\hline Resultado Financeiro & 0,000 & $-0,000$ & Despesa com Pessoal & $-0,218 * * *$ & $-0,549 * * *$ \\
\hline Dívida Ativa & $0,053 *$ & $-0,009$ & Despesa com Investimentos & $1,274 * * *$ & $0,868 * * *$ \\
\hline Endividamento & $-0,009$ & $-0,001$ & Constante & $0,110 *$ & $0,090 * * *$ \\
\hline Qui-Quadrado & $833,22 * * *$ & $501,49 * * *$ & LV statistic & 339,83 & 294,84 \\
\hline Observações & 262 & 269 & & & \\
\hline
\end{tabular}

Nota. Os dados sinalizam como os indicadores contábeis explicam a condição fiscal dos municípios brasileiros a partir de um conjunto de informações atribuídas aos Ciclos Político-Contábeis. O coeficiente expressa se a associação estabelecida é positiva ou negativa e a magnitude da significância estatística é indicada por meio do p-valor: *p-valor $<0,1$; **p-valor $<0,05$; ***p-valor $<0,01$. Fonte: Elaboração própria com base nos dados de: Sistema FIRJAN. (2017, August). Índice Firjan de Gestão Fiscal [IFGF]: recorte municipal (abrangência nacional), ano base 2013. Retrieved from http://www.firjan.com.br/ifgf/consulta-ao-indice/; e Siconfi. (n.d.). Sistema de Informações Contábeis e Fiscais do Setor Público Brasileiro [Siconfi]. Retrieved from https://siconfi.tesouro.gov.br/siconfi

De maneira geral, os indicadores contábeis com potencial relação aos ciclos políticos explicam a situação fiscal dos municípios na medida em que (a) os Restos a Pagar podem ser utilizados como ferramenta para postergação da despesa pública e financiador do equilíbrio orçamentário; (b) municípios com melhores condições de gerarem caixa ou explorarem a capacidade de geração de fluxos de ingressos por meio das receitas tributárias tendem a possuir melhores condições fiscais; e (c) os gastos com pessoal, indicativos da rigidez nos orçamentos municipais, e a relação apresentada para os investimentos e resultados orçamentários mostram que quanto mais recursos forem comprometidos com o pagamento de servidores e aposentados, por exemplo, espera-se que menor seja a capacidade de aplicarem recursos em outras áreas, como os investimentos, podendo dificultar também o alcance do equilíbrio orçamentário.

\section{Perspectiva política sobre a gestão fiscal}

Na Tabela 4 estão os resultados das estimativas que buscam verificar como a possibilidade de reeleição, os mandatos e os anos eleitorais estão relacionados com a gestão fiscal dos municípios. Ressalta-se que foram estimados dois modelos, o primeiro considerando os prefeitos reeleitos nas eleições de 2008, 2012 e 2016 e, o segundo, com os gestores no primeiro mandato.

Inicialmente, observa-se uma relação positiva entre o ano eleitoral e o mandato eleitoral dos prefeitos reeleitos com a gestão fiscal dos municípios. Na segunda etapa, a relação observada para as gestões em primeiro mandato é negativa. 
Tabela 4. Relação entre a Condição Fiscal dos Municípios e Indicadores Político-Eleitorais.

\begin{tabular}{|c|c|c|c|}
\hline Variáveis & Etapa I - Prefeitos Reeleitos & Variáveis & $\begin{array}{c}\text { Etapa II - Prefeitos em Primeiro } \\
\text { Mandato }\end{array}$ \\
\hline Ano Eleitoral & $0,021 * * *$ & Ano Eleitoral & $0,021 * * *$ \\
\hline Prefeito Reeleito & $0,022 * * *$ & Primeiro Mandato & $-0,022 * * *$ \\
\hline Partidos Reconduzidos & 0,008 & Partidos Reconduzidos & 0,008 \\
\hline Constante & $0,469 * * *$ & Constante & $0,492 * * *$ \\
\hline LV statistic & $103,53 * * *$ & & $103,53 * * *$ \\
\hline Observações & 3.596 & & 3.596 \\
\hline
\end{tabular}

Nota. Aponta como as variáveis políticas influenciam a qualidade fiscal dos municípios. O coeficiente expressa se a associação estabelecida é positiva ou negativa e a magnitude da significância estatística é indicada por meio do p-valor: *p-valor < 0,1; $*$ p-valor < 0,05; ***p-valor < 0,01. Fonte: Elaboração própria com base nos dados de: Sistema FIRJAN. (2017, August). Índice Firjan de Gestão Fiscal [IFGF]: recorte municipal (abrangência nacional), ano base 2013. Retrieved from http://www.firjan.com.br/ifgf/consulta-aoindice/; e TSE. (n.d.). Tribunal Superior Eleitoral [TSE]: estatísticas. Retrieved from http://www.tse.jus.br/eleicoes/estatisticas/estatisticas

Esses resultados demonstram que os prefeitos reeleitos alcançaram níveis superiores na qualidade fiscal, havendo também melhoras significativas em períodos estratégicos, como em anos eleitorais. Tais achados convergem com estudos prévios indicando que apesar dos eleitores possuírem preferências pelo aumento do gasto em todo o mandato (Arvate, Mendes, $\&$ Rocha, 2010) e que os prefeitos que aumentam as despesas em momentos eleitorais possuem maiores chances de reeleição, essa elevação só é tolerável caso esteja dentro dos limites de déficits aceitos pelos votantes (Drazen \& Eslava, 2005; Brender \& Drazen, 2008; Klein, 2010).

Portanto, a relação positiva entre os prefeitos reeleitos e a gestão fiscal dos municípios pode ser resultante da capacidade dos eleitores avaliarem a situação fiscal das gestões locais, ou ainda decorrente da capacidade desses gestores fornecerem um maior nível de bens e serviços públicos. Essas conjunções podem se intensificar em anos eleitorais, seja em decorrência da sinalização da sua competência ou em consequência da visibilidade que alcançam nesse período.

Nesse sentido, a Tabela 5 busca identificar como os indicadores do IFGF se comportam em anos eleitorais, período estratégico em que os governantes possuem incentivos em aumentar a despesa pública (Shi \& Svensson, 2006; Veiga \& Veiga, 2007a). Em virtude da indisponibilidade de dados do IFGF cobrindo todo o ciclo político de 2008 (mais especificamente o ano de 2005), optou-se pela sua introdução apenas no modelo consolidado.
Tabela 5. Relação entre o Ano Eleitoral e os Indicadores que compõem o IFGF.

\begin{tabular}{lccc}
\hline Variáveis & $\begin{array}{c}\text { Ciclo Político } \\
2009-2012\end{array}$ & $\begin{array}{c}\text { Ciclo Político } \\
2013-2016\end{array}$ & $\begin{array}{c}\text { Consolidado } \\
2006-2016\end{array}$ \\
\hline $\begin{array}{l}\text { Custo da } \\
\text { Dívida }\end{array}$ & $-0,591$ & 0,497 & $-0,570 *$ \\
$\begin{array}{l}\text { Gastos com } \\
\text { Pessoal }\end{array}$ & $-2,455 * * *$ & 0,506 & $0,446 * *$ \\
Investimentos & $1,737 * * *$ & $-2,080 * * *$ & $0,465 * * *$ \\
Liquidez & $-0,374$ & $1,402 * * *$ & $0,743 * * *$ \\
Receita Própria & 1,000 & 1,637 & $-0,936$ \\
\hline LV statistic & $69,72 * * *$ & $79,88 * * *$ & $49,52 * * *$ \\
Observações & 1.571 & 1.142 & 4.442 \\
\hline
\end{tabular}

Nota. Auxilia a entender como os indicadores da gestão fiscal que formam o IFGF se comportam nos anos eleitorais. A coluna com informacões consolidadas abrange toda a base de dados (2006-2016), cobrindo o período eleitoral de 2008, 2012 e 2016. O coeficiente expressa se a associação estabelecida é positiva ou negativa e a magnitude da significância estatística é indicada por meio do p-valor: *p-valor $<0,1$; **p-valor $<0,05$; *** p-valor $<0,01$ Fonte: Elaboração própria com base nos dados de: Sistema FIRJAN. (2017, August). Índice Firjan de Gestão Fiscal [IFGF]: recorte municipal (abrangência nacional), ano base 2013. Retrieved from http://www.firjan.com.br/ifgf/consulta-ao-indice/

Com base nos resultados da Tabela 5, é possível observar como se comportam os indicadores fiscais em anos eleitorais para toda a série histórica disponibilizada (2006-2016). Com exceção da Receita Própria, os demais indicadores apresentam variações significativas, sendo possível verificar que os representativos dos Gastos com Pessoal, Investimentos e Liquidez aumentaram entre os anos, enquanto o Custo da Dívida diminuiu.

Entre os itens que formam o IFGF, o Custo da Dívida é apontado como sendo o melhor em termos avaliativos (Sistema FIRJAN, 2017). Em 2016, apenas 
$8,10 \%$ dos municípios estavam em dificuldade com o pagamento de juros e amortizações da dívida. Nos três anos eleitorais, o índice médio para a Dívida Consolidada Líquida era de 0,936 (conceito Excelente), indicando baixo comprometimento do orçamento para amortização das dívidas contraídas em exercícios anteriores. Portanto, apesar da relação negativa no ano eleitoral, o indicador não parece representar uma complicação efetiva da situação fiscal dos municípios, que continuam em níveis satisfatórios para tal medida.

As despesas com Investimento aumentam de forma significativa nos anos eleitorais dos ciclos em estudo. Essa relação era esperada levando em consideração que os investimentos são valorizados nesse período (Eslava, 2005) e estão associados positivamente ao percentual de votos recebidos pelo prefeito em mandato (Veiga \& Veiga, 2007b). Isso ocorre porque os eleitores são simpáticos a determinados gastos e utilizam os bens fornecidos pelos governantes para avaliar as suas prioridades fiscais, sendo as despesas de capital favoráveis nesse sentido (Drazen \& Eslava, 2010; Sakurai \& Menezes, 2008; Klein \& Sakurai, 2015; Queiroz, 2015).

O Gasto com Pessoal é o indicador mais crítico entre os componentes do IFGF e, apesar de apresentar uma melhoria nos anos eleitorais, esse resultado pode ser consequência da proibição de aumento da despesa com servidores nos seis últimos meses de mandato, como determina a LRF, que é uma iniciativa do prefeito para buscar uma gestão mais responsável nessa categoria. Ainda assim, o peso no orçamento para o pagamento dessas despesas prejudica a gestão fiscal dos municípios durante todo o período em que a metodologia foi disponibilizada.

No segundo ciclo (2013-2016), etapa com maior percentual de prefeituras em situação fiscal difícil desde a criação da metodologia pelo Sistema Firjan, cerca de $26 \%$ das gestões com informações disponíveis para o Relatório de Gestão Fiscal (RGF) desobedeceram ao limite prudencial de $54 \%$ da Receita Corrente Líquida (RCL) com despesa de pessoal para o executivo municipal. No primeiro ciclo, esse descumprimento atingiu $15,30 \%$ das instituições analisadas.

Ademais, nota-se uma relação positiva entre o índice de Liquidez dos municípios e o período com eleição. Tal fato pode ser decorrente de um esforço dos prefeitos deixarem recursos suficientes para honrar as despesas postergadas para o exercício seguinte no ano eleitoral, como determina a LRF. Ainda assim, cerca de $27 \%$ das observações eram de prefeituras com liquidez zero entre 2006-2016, convergindo com as discussões do Sistema Firjan de que os municípios estão postergando despesas via restos a pagar como mecanismo de ajuste orçamentário sem recursos suficientes para honrálas.

A Tabela 6 demonstra como a gestão fiscal dos municípios se comporta frente à competitividade eleitoral e como as diferenças ideológicas podem influenciar sua condição fiscal.

Tabela 6. Relação entre a Gestão Fiscal e Indicadores da Competição Política, Ideológicos e de Controle.

\begin{tabular}{|c|c|c|c|c|}
\hline Variáveis & Ciclo Político de 2008 & Ciclo Político de 2012 & Ciclo Político de 2016 & Consolidado \\
\hline Competição Política & $0,013 * * *$ & 0,004 & 0,006 & $0,008 * *$ \\
\hline$\%$ Votos Recebidos & $0,001 * *$ & $0,001 * *$ & 0,000 & $0,000 * * *$ \\
\hline Partidos de Direita & $-0,003$ & $-0,029 * *$ & $-0,013$ & $-0,016 * *$ \\
\hline Partidos de Esquerda & 0,002 & $-0,026 *$ & $-0,027 *$ & $-0,016 *$ \\
\hline Outros Partidos & $-0,138$ & 0,063 & $-0,032$ & $-0,079$ \\
\hline LAI & - & - & - & $-0,044 * * *$ \\
\hline Constante & $0,377 * * *$ & $0,447 * * *$ & $0,4346 * * *$ & $0,444 * * *$ \\
\hline LV statistic & $12,09 * * *$ & 7,75 & 5,30 & $51,14 * * *$ \\
\hline Observações & 422 & 423 & 422 & 1.267 \\
\hline
\end{tabular}

Nota. Demonstra a relação estabelecida entre a gestão fiscal e um conjunto de indicadores representativos da competição política, ideologia partidária do prefeito e o estímulo à transparência por meio da Lei de Acesso à Informação (LAI). O coeficiente expressa se a associação é positiva ou negativa e a magnitude da significância estatística é indicada por meio do p-valor: *p-valor < 0,1; **p-valor < 0,05; ***p-valor < 0,01. Fonte: Elaboração própria com base nos dados de: Sistema FIRJAN. (2017, August). Índice Firjan de Gestão Fiscal [IFGF]: recorte municipal (abrangência nacional), ano base 2013. Retrieved from http://www.firjan.com.br/ifgf/consulta-ao-indice/; e TSE. (n.d.). Tribunal Superior Eleitoral [TSE]: estatísticas. Retrieved from http://www.tse.jus.br/eleicoes/estatisticas/estatisticas 
Os achados para a competição política (a nível consolidado e no ciclo de 2008) indicam que a competitividade eleitoral exerce uma influência positiva na qualidade da gestão fiscal. Ou seja, quanto mais partidos políticos estiverem no pleito e mais disputada for a corrida pelo cargo, maior a responsabilidade do prefeito durante o ciclo político. Uma possível explicação é que, com alta competitividade, os partidos tendem a fiscalizar uns aos outros com o objetivo de evidenciar falhas de gestão ou condutas que os eleitores desaprovam, gerando um ambiente de policiamento das atividades públicas.

Outro aspecto dessa relação é que o percentual de votos recebidos pelo incumbente também está positivamente relacionado à qualidade da gestão fiscal. Isso pode ser reflexo da tentativa de construção de uma reputação junto aos eleitores como forma de retribuir o apoio dado nas urnas, pois a continuidade no cargo depende de como o político responde às preferências fiscais dos votantes (Klein \& Sakurai, 2015).

Na avaliação ideológica, vê-se que tanto os partidos de direita, quanto os de esquerda, apresentam uma gestão fiscal inferior aos de centro (PMDB e PSDB) nos ciclos individuais (2012 e 2016) e no consolidado. Ao considerarmos as preferências partidárias abordadas por Hibbs (1977), nota-se que o equilíbrio das contas públicas é a segunda prioridade dos governos de direita, o que não se confirma ao avaliarmos a gestão local das prefeituras comandadas por esses partidos, que possuem desempenho fiscal inferior aos de centro (grupo de referência). Já os de esquerda possuem como última prioridade o equilíbrio das contas, pois suas preferências estão para o pleno emprego. No cenário analisado, tanto os partidos de esquerda, quanto os de direita, possuem níveis fiscais inferiores em relação aos de centro.

Por fim, observa-se uma associação negativa entre a LAI e a qualidade na gestão fiscal dos municípios, contrariando estudos indicando que a transparência das atividades públicas torna a manipulação na política fiscal menos eficaz e diminui a ocorrência e a intensidade dos ciclos políticos (Shi \& Svensson, 2006; Veiga \& Veiga, 2007b; Klomp \& Haan, 2013). No entanto, salienta-se que a LAI entrou em vigor em 2012 e sua aplicação se deu em um período de extensa crise política e econômica que culminou no desequilíbrio fiscal de várias instituições, o que pode ter refletido nos resultados.

\section{Avaliação dos resultados eleitorais}

A Tabela 7 evidencia como os indicadores da gestão fiscal se comportam em anos eleitorais entre os partidos reconduzidos. Destaca-se que o Custo da Dívida em 2008 foi excluído em decorrência da multicolinearidade verificada com base no teste VIF.

Tabela 7. Relação entre os Indicadores da Gestão Fiscal nos Anos Eleitorais e a Recondução dos Partidos Políticos.

\begin{tabular}{|c|c|c|c|c|}
\hline Variáveis & Eleições 2008 & Eleições 2012 & Eleições 2016 & Consolidado \\
\hline Custo da Dívida & - & $-1,362 * *$ & $-0,537$ & $-0,774 * *$ \\
\hline $\begin{array}{l}\text { Gastos com } \\
\text { Pessoal }\end{array}$ & $1,773 * *$ & $-0,068$ & $1,704 * *$ & $0,959 * * *$ \\
\hline Investimentos & 0,183 & $1,393 \ldots *$ & 0,690 & $0,721 * * *$ \\
\hline Liquidez & $1,170 * * *$ & $0,712 * *$ & $-0,194$ & $0,627 * *$ \\
\hline Receita Própria & $-0,230$ & $-0,803$ & $-0,676$ & $-0,572 *$ \\
\hline Constante & $-2,601$ 米 & $-0,880$ & $-1,439 *$ & $-1,410 * * *$ \\
\hline LV statistic & $19,04 * * *$ & $19,61 * * *$ & $10,61 *$ & $37,54 * * *$ \\
\hline Pseudo R2 & $3,64 \%$ & $4,15 \%$ & $2,51 \%$ & $2,64 \%$ \\
\hline Observações & 410 & 395 & 361 & 1.166 \\
\hline
\end{tabular}

Teste de Média dos Componentes do IFGF para os Partidos Políticos

\begin{tabular}{lccc} 
Indicadores & Partidos Não Reconduzidos & Partidos Reconduzidos & Mann-Whitney \\
\hline IFGF Geral & 0,494 & 0,533 & $0,000 *, 188$ \\
Custo da Dívida & 0,805 & 0,793 & $0,000 * * * * *$ \\
Gastos com Pessoal & 0,573 & 0,622 & $0,000 * * * *$ \\
Investimentos & 0,523 & 0,598 & $0,000 * * * *$ \\
Liquidez & 0,496 & 0,563 & 0,105 \\
Receita Própria & 0,245 & 0,236 & \\
\hline
\end{tabular}

Nota. Evidencia como os indicadores da gestão fiscal se comportam em anos eleitorais entre os partidos que conseguiram ser reconduzidos. Além disso, procedeu-se com o teste de média para verificar se os indicadores fiscais se diferem entre os grupos. O coeficiente expressa se a associação estabelecida é positiva ou negativa e a magnitude da significância estatística é indicada por meio do p-valor: *p-valor $<0,1 ; * *$ p-valor $<0,05$; ***p-valor $<0,01$. Fonte: Elaboração própria com base nos dados de: Sistema FIRJAN. (2017, August). Índice Firjan de Gestão Fiscal [IFGF]: recorte municipal (abrangência nacional), ano base 2013. Retrieved from http://www.firjan.com.br/ifgf/consulta-ao-indice/; e TSE. (n.d.). Tribunal Superior Eleitoral [TSE]: estatísticas. Retrieved from http://www.tse.jus.br/eleicoes/estatisticas/estatisticas 
Na análise do modelo consolidado é possível verificar que com exceção do Custo da Dívida e da Receita Própria, os demais indicadores possuem uma relação positiva e significativa com a recondução dos partidos políticos nas três últimas eleições. A relação negativa observada para a receita própria reflete a baixa autossuficiência financeira dos municípios. Nesse aspecto, as transferências intergovernamentais são um suporte necessário para a prestação de bens e serviços públicos à sociedade.

Já os resultados para o custo da dívida mostram que os partidos reconduzidos tiveram maiores gastos com juros e amortizações. Essa associação não indica que a gestão fiscal do município seja necessariamente prejudicada ou que obtenha menores níveis no IFGF Global com base nesse indicador. Aliado a esse fato, na análise do RGF para a folga em relação ao limite preestabelecido pela LRF, apenas três municípios ultrapassaram o teto de $120 \%$ da RCL, com margens médias superiores a $85 \%$ do limite nas três eleições.

Ressalta-se que, com base no teste de média para os componentes do IFGF entre os partidos reconduzidos e não reconduzidos entre as eleições, não é possível afirmar que as médias entre os grupos para o Custo da Dívida e Receita Própria sejam estatisticamente distintas. Ou seja, a baixa autonomia financeira não é exclusiva aos municípios com recondução partidária e o dispêndio de recursos com a Dívida Consolidada Líquida não distancia significativamente a qualidade fiscal das gestões.

Na avaliação dos demais indicadores (Gastos com Pessoal, Investimentos e Liquidez) é possível constatar que: (a) os partidos reconduzidos desenvolveram uma gestão fiscal mais responsável sobre os gastos com pessoal; (b) alocaram mais recursos em investimentos como proporção da RCL; e (c) possuem melhores condições de honrar seus compromissos de curto prazo. Para além disso, as estimações demonstram que as relações são positivas e significativas e as médias entre os grupos diferem de acordo com o Teste de Mann-Whitney.

Na análise individual dos indicadores no teste de média, nota-se que os partidos reconduzidos aplicarammaiorvolume derecursos emInvestimentos, sendo necessário que as instituições alocassem ao menos $20 \%$ da RCL para alcançarem nota máxima. Isso significa que os partidos reconduzidos dedicaram um maior volume de recursos em áreas relativas a pavimentação de ruas, construção de praças ou obras diversas se comparados aos não reconduzidos. Esse resultado está alinhado aos Modelos Racionais Oportunistas discutidos inicialmente por Rogoff e Sibert (1988) e Rogoff (1990).

No entanto, se analisarmos sob o aspecto da assimetria de informação temporária indicada por Rogoff (1990), ela não é explorada a partir de uma gestão fiscal irresponsável no ano eleitoral. Isso porque o IFGF Geral médio dos municípios com recondução partidária $(0,533)$ é superior aos demais $(0,494)$ e segue uma tendência similar às Despesas com Pessoal e Liquidez, refletindo uma melhora na situação fiscal de forma mais abrangente.

Tais resultados se aproximam de algumas contribuições teóricas internacionais afirmando que os políticos vão buscar fornecer os bens e serviços que os votantes valorizam, mas que déficits fiscais são evitados pelo impacto negativo que podem exercer nos eleitores (Eslava, 2005; Vergne, 2009). Ou ainda que o apoio ao incumbente só acontece quando as alterações na composição dos gastos não prejudica o desempenho fiscal dos municípios (Drazen \& Eslava, 2005; Brender \& Drazen, 2008).

No contexto brasileiro, a literatura indica que os prefeitos possuem incentivos em impulsionar os gastos em anos eleitorais (Sakurai, 2005; Sakurai \& Menezes, 2011) ou alterar a composição da despesa pública para áreas finalísticas (Sakurai \& Menezes, 2008; Queiroz, 2015). Já os eleitores se mostram favoráveis ao aumento dos gastos em todo o período eleitoreiro e são receptíveis aos investimentos de capital (Arvate, Mendes, \& Rocha, 2010; Klein \& Sakurai, 2015). No entanto, essa receptividade só acontece caso esteja dentro dos limites de déficits aceitos pelos eleitores, o que não implica obrigatoriamente no desequilíbrio das finanças municipais (Klein, 2010).

Os resultados reforçam que os investimentos exerceram um efeito positivo na recondução dos partidos políticos nas últimas eleições. No entanto, para além do aumento dos investimentos, as gestões recompensadas possuem também melhores condições fiscais de maneira geral, mantendo uma estrutura de servidores mais adequada às determinações legais, além de possuirem recursos suficientes para atender suas obrigações de curto prazo no ano eleitoral. Tais achados abrangem as contribuições dos estudos até então desenvolvidos.

Por fim, na Tabela 8 estão as estimações que visam verificar como a condição fiscal se comporta durante o ciclo político e no período pós-eleitoral. 
Tabela 8. Relação entre o IFGF Geral e o Ciclo Político abrangendo o Período Pós-Eleitoral.

\begin{tabular}{lccccc}
\hline & \multicolumn{2}{c}{ Partidos Políticos Reconduzidos } & \multicolumn{2}{c}{ Partidos Políticos Não Reconduzidos } \\
Variáveis & Ciclo 2008 & Ciclo 2012 & Ciclo 2016 & Ciclo 2008 & Ciclo 2012 \\
\hline Ano Pré-Eleitoral & 0,001 & $0,016 *$ & $-0,040 * * *$ & $-0,003$ & $-0,007$ \\
Ano Eleitoral & $0,050 * * *$ & 0,012 & $0,016 *$ & $0,029 * * *$ & $-0,013 * *$ \\
Ano Pós-Eleitoral & $-0,009$ & $-0,019 * *$ & - & $-0,028 * * *$ & $-0,067 * * *$ \\
Constante & $0,515 * * *$ & $0,512 * * *$ & $0,501 * * *$ & $0,487 * * *$ & $0,019 * * *$ \\
\hline LV statistic & $59,13 * * *$ & $17,14 * * *$ & $19,03 * * *$ & $69,96 * * *$ & $124,11 * * *$ \\
Observações & 553 & 481 & 300 & 1.113 & $0,474 * * *$ \\
\hline
\end{tabular}

Teste de Média do IFGF Geral para os Partidos Políticos

Ciclo de 2008

Ciclo de 2012

Ciclo de 2016

Partidos Reconduzidos

Partidos Reconduzidos

\begin{tabular}{lccccccccccc} 
Variáveis & Sim & Não & M-W & Sim & Não & M-W & Sim & Não & M-W \\
\cline { 2 - 8 } II Ano & 0,515 & 0,488 & 0,025 & 0,512 & 0,510 & 0,833 & 0,500 & 0,476 & 0,131 \\
Pré-Eleitoral & 0,516 & 0,484 & 0,016 & 0,529 & 0,503 & $0,050 *$ & 0,460 & 0,441 & 0,149 \\
Ano Eleitoral & 0,565 & 0,518 & 0,000 & 0,533 & 0,498 & $0,019 *$ & 0,490 & 0,465 & $0,064 *$ \\
Pós-Eleitoral & 0,506 & 0,458 & 0,002 & 0,494 & 0,445 & $0,002 * * *$ & - & -
\end{tabular}

Nota. Permite observar como a condição fiscal se comporta durante o ciclo político e o período pós-eleitoral. Além disso, procedeu-se com o teste de média (Mann-Whitney: M-W) para verificar se o IFGF se difere entre os grupos. O coeficiente expressa se a associação estabelecida é positiva ou negativa e a magnitude da significância estatística é indicada por meio do $p$-valor: *p-valor $<0,1 ; * * p$-valor $<0,05$; ***p-valor $<0,01$. Fonte: Elaboração própria com base nos dados de: Sistema FIRJAN. (2017, August). Índice Firjan de Gestão Fiscal [IFGF]: recorte municipal (abrangência nacional), ano base 2013. Retrieved from http://www.firjan.com.br/ifgf/consulta-ao-indice/

Na análise específica entre os grupos notase uma relação positiva entre a gestão fiscal e o ano eleitoral entre os partidos reconduzidos (com estimações significativas para o ciclo de 2008 e 2016). Entre os não reconduzidos essa associação ocorre apenas em 2008, com sinal inverso para a análise estabelecida em 2012 e 2016. Esse resultado é compatível às discussões prévias para o comportamento dos componentes do IFGF Geral e a recondução partidária. Por outro lado, a relação observada para o período pós-eleitoral é negativa em ambos os grupos, indicando que o primeiro ano de mandato é um período de dificuldade fiscal independentemente da recondução.

Nota-se que os partidos reconduzidos obtiveram médias superiores na situação fiscal em todos os anos dos três ciclos. Nos anos eleitorais, o desempenho fiscal médio desses municípios é superior em patamares que variam entre 6\% (2016) e 9\% (2008). No entanto, no ano pós-eleitoral, a situação fiscal cai cerca de 10,40\% em relação a 2008 e $7,30 \%$ em relação a 2012, indicando que o efeito dessa sinalização se inverte no ano seguinte.

Portanto, os políticos podem utilizar como estratégia a prorrogação de despesas e os efeitos das decisões tomadas no ano eleitoral para o período subsequente. Como as consequências dessas ações só estarão disponíveis no futuro, os eleitores não teriam acesso a essas informações para a decisão do voto e os prefeitos não seriam prejudicados, nesse momento, pelo conservadorismo sinalizado por Klein (2010) e Klein e Sakurai (2015).

\section{CONCLUSÃO}

$\mathrm{Na}$ análise da gestão fiscal dos municípios brasileiros com base nos ciclos políticos, o presente estudo trouxe duas contribuições principais. A primeira é que, embora exista um aumento nos gastos com investimentos em períodos estratégicos entre os partidos reconduzidos, como indica a literatura (Sakurai \& Menezes, 2008; Drazen \& Eslava, 2010; Klein \& Sakurai, 2015; Queiroz, 2015), sua elevação não decorre de um negligenciamento na gestão fiscal dos municípios, isso porque essas instituições também desenvolveram uma administração mais responsável sobre os gastos com pessoal e possuem melhores condições de honrar seus compromissos de curto prazo. Portanto, resultados eleitorais favoráveis são atribuídos aos prefeitos com melhores condições fiscais de maneira geral. 
A segunda é que mesmo havendo uma relação positiva entre a recondução dos partidos e a condição fiscal no ano eleitoral, o efeito da sinalização se inverte no período pós-eleitoral. Como o impacto das decisões dos prefeitos só estará disponível para os eleitores no período seguinte, os políticos podem utilizar de estratégias fiscais para evitar que o equilíbrio fiscal do período corrente seja prejudicado e, assim, postergar o desembolso para o ano subsequente, uma decisão que não prejudicaria o desempenho atual e o recebimento de votos. Esse resultado é compatível com a assimetria da informação temporária indicada

\section{REFERÊNCIAS}

Akerman, J. (1947). Political economic cycles. International Review for Social Sciences, 1(2), 107-117. https://doi. org/10.1111/j.1467-6435.1947.tb00420.x

Alesina, A. (1987). Macroeconomic policy in a two-party system as a repeated game. Quarterly Journal of Economics, 102(3), 651-678. https://doi.org/10.2307/1884222

Arvate, P. R., Mendes, M., \& Rocha, A. (2010). Are voters fiscal conservatives? Evidence from brazilian municipal elections. Estudos Econômicos, 40(1), 67-101. http:// dx.doi.org/10.1590/S0101-41612010000100003

Block, S. A. (2002). Political business cycles, democratization, and economic reform: The case of Africa. Journal of Development Economics, 67(1), 205-228. https://doi. org/10.1016/S0304-3878(01)00184-5

Brender, A., \& Drazen, A. (2003). Where does the political budget cycle really come from? CEPR Discussion Paper, (4049). Retrieved from https://ssrn.com/abstract $=462820$

Brender, A., \& Drazen, A. (2008). How do budget deficits and economic growth affect reelection prospects? Evidence from a large panel of countries. The American Economic Review, 98(5), 2203-2220. Retrieved from www.jstor.org/ stable/29730168

Cameron, A. C., \& Trivedi, P. K. (2005). Microeconometrics: methods and applications. Cambridge: Cambridge University Press.

Downs, A. (1957). An economic theory of political action in a democracy. Journal of Political Economy, 65(2), 135-150. https://doi.org/10.1086/257897

Drazen, A., \& Eslava, M. (2005) Electoral manipulation via expenditure composition: Theory and evidence [Working Paper n. 11085]. National Bureau of Economic Research, Cambridge, MA, USA. https://doi.org/10.3386/w11085

Drazen, A., \& Eslava, M. (2010). Electoral manipulation via voter-friendly spending: Theory and evidence. Journal of Development Economics, 92(1), 39-52. https://doi. org/10.1016/j.jdeveco.2009.01.001 nos estudos de expectativas racionais nos Ciclos Político-Orçamentários.

Ademais, os indicadores com potencial relação aos "Ciclos Político-Contábeis" ajudam a explicar a condição fiscal dos municípios. Além disso, aspectos da competição política auxiliam a compreender a responsabilidade fiscal da gestão em exercício. E ideologicamente, os partidos de Centro tendem a ser mais responsáveis em relação aos de Direita e Esquerda.

Eslava, M. (2005). Political budget cycles or voters as fiscal conservatives? Evidence from Colombia. Documentos CEDE 003343, Universidad de Los Andes - CEDE, 1-38. Retrieved from https://ideas.repec.org/p/col/000089/003343.html

Eslava, M. (2011). The political economy of fiscal deficits: A survey. Journal of Economic Surveys, 25(4), 645-673. https://doi.org/10.1111/j.1467-6419.2010.00647.x

Hibbs, D. A, (1977). Political parties and macroeconomic policy. American Political Science Review, 71(4), 1467-1487. https://doi.org/10.1017/S0003055400269712

Sistema FIRJAN. (2017, August). Índice Firjan de Gestão Fiscal [IFGF]: recorte municipal (abrangência nacional), ano base 2013. Retrieved from http://www.firjan.com.br/ifgf/ consulta-ao-indice/

Kalecki, M. (1943). Political aspects of full employment The Political Quarterly, 14(4), 322-330. https://doi. org/10.1111/j.1467-923X.1943.tb01016.x

Klein, F. A. (2010). Reelection incentives and political budget cycle: Evidence from Brazil. Revista de Administração Pública, 44(2), 283-337. http://dx.doi.org/10.1590/S003476122010000200006

Klein, F. A., \& Sakurai, S. N. (2015). Term limits and political budget cycles at the local level: Evidence from a young democracy. European Journal of Political Economy, 37, 21 36. https://doi.org/10.1016/j.ejpoleco.2014.10.008

Klomp, J., \& Haan, J. (2013). Do political budget cycles really exist? Applied Economics, 45(3), 329-341. https://doi.org $/ 10.1080 / 00036846.2011 .599787$

Nordhaus, W. D. (1975). The political business cycle. The Review of Economic Studies, 42(2), 169-190. https://doi. org/10.2307/2296528

Peltzman, S. (1992). Voters as fiscal conservatives. The Quarterly Journal of Economics, 107(2), 327-361. https://doi. org/10.2307/2118475

Queiroz, D. B. (2015). Composição dos gastos públicos e resultados eleitorais: Um estudo nos municípios brasileiros (Doctoral Dissertation). UNB, UFPB e UFRN, Programa MultiInstitucional e Inter-Regional de Pós-Graduação em Ciências Contábeis, Natal, RN, Brazil. Retrieved from http:// repositorio.unb.br/bitstream/10482/19215/1/2015_ DimasBarretodeQueiroz.pdf 
Rogoff, K. (1990). Equilibrium political budget cycles. The American Economic Review, 80(1), 21-36. Retrieved from https://www.jstor.org/stable/2006731

Rogoff, K., \& Sibert, A. (1988). Elections and macroeconomic policy cycles. The Review of Economic Studies, 55(1), 1-16. https://doi.org/10.2307/2297526

Rose, S. (2006). Do fiscal rules dampen the political business cycle? Public Choice, 128(3-4), 407-431. https://doi. org/10.1007/s11127-005-9007-7

Sakurai, S. N. (2005). Testando a hipótese de ciclos eleitorais racionais nas eleições dos municípios paulistas. Estudos Econômicos, 35(2), 297-315. https://dx.doi.org/10.1590/ S0101-41612005000200003

Sakurai, S. N., \& Menezes, N. A, Filho. (2008). Fiscal policy and reelection in Brazilian municipalities. Public Choice, 137(12), 301-314. https://doi.org/10.1007/s11127-008-9329-3

Sakurai, S. N., \& Menezes, N. A, Filho. (2011). Opportunistic and partisan election cycles in Brazil: New evidence at the municipal level. Public Choice, 148(1-2), 233-247. https:// doi.org/ 10.1007/s11127-010-9654-1

Siconfi. (n.d.). Sistema de Informações Contábeis e Fiscais do Setor Público Brasileiro [Siconfi]. Retrieved from https://siconfi. tesouro.gov.br/siconfi

Shi, M., \& Svensson, J. (2006). Political budget cycles: Do they differ across countries and why? Journal of Public Economics, 90(8-9), 1367-1389. https://doi.org/10.1016/j. jpubeco.2005.09.009

\section{Autores}

\section{Alann Inaldo Silva de Sá Bartoluzzio*}

Av. Prof. Moraes Rego, 1235, Cidade Universitária, 50670-901, Recife, PB, Brasil

E-mail: alannbartoluzzio@hotmail.com

(D) https://orcid.org/0000-0002-0046-4513

\section{Luiz Carlos Marques dos Anjos}

Av. dos Economistas, s/n, $1^{\circ}$ andar, Cidade Universitária, 50640-040, Recife, PB, Brasil

E-mail: luiz.cmanjos@ufpe.br

https://orcid.org/0000-0002-7375-540X

* Autor Correspondente

\section{Contribuições}

$1^{\circ}$ autor: liderou a conceituação, curação de dados, análise formal, pesquisa, metodologia, administração do projeto, escrita do rascunho original, escrita, revisão e edição do texto final.

$2^{\mathbf{0}}$ autor: liderou a supervisão, atuou como apoio à conceituação, análise formal, metodologia, administração do projeto e validação
Speck, B. W., Braga, M. S. S., \& Costa, V. (2015). Estudo exploratório sobre filiação e identificação partidária no Brasil. Revista de Sociologia Política, 23(56), 125-148. http://dx.doi. org/10.1590/1678-987315235606

STN. (n.d.). Secretaria do Tesouro Nacional [STN]: finanças estaduais e municipais. Retrieved from https://www. tesouro.fazenda.gov.br/-/area-tematica-4-financasestaduais-e-municipais

Streb, J. M., Lema, D., \& Torrens, G. (2009). Checks and balances on political budget cycles: Cross-country evidence. International Review for Social Sciences, 62(3), 426-447. https://doi.org/10.1111/j.1467-6435.2009.00444.x

TSE. (n.d.). Tribunal Superior Eleitoral [TSE]: estatísticas. Retrieved from http://www.tse.jus.br/eleicoes/estatisticas/ estatisticas

Veiga, L. G., \& Veiga, F. J. (2007a). Political business cycles at the municipal level. Public Choice, 131(1-2), 45-64. https:// doi.org/10.1007/s11127-006-9104-2

Veiga, L. G., \& Veiga, F. J. (2007b). Does opportunism pay off? Economics Letters, 96(2), 177-182. https://doi. org/10.1016/j.econlet.2006.12.026

Vergne, C. (2009). Democracy, elections and allocation of public expenditures in developing countries. European Journal of Political Economy, 25(1), 63-77. https://doi.org/10.1016/j. ejpoleco.2008.09.003

Vicente, E. F. R., \& Nascimento, L. S. (2012). A efetividade dos ciclos políticos nos municípios brasileiros: Um enfoque contábil. Revista de Contabilidade e Organizações, 6(14), 106-126. https://doi.org/10.11606/rco.v6i14.45402

\section{Financiamento}

Os autores informaram que não houve apoio financeiro para a pesquisa neste artigo.

\section{Conflito de Interesses}

Os autores informaram que não há conflito de interesses.

\section{Verificação de Plágio}

A RAC mantém a prática de submeter todos os documentos aprovados para publicação à verificação de plágio, mediante o emprego de ferramentas específicas, e.g.: iThenticate.

\section{Material Suplementar}

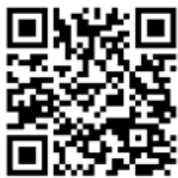

Todos os dados e materiais foram disponibilizados publicamente por meio da plataforma Mendeley e podem ser acessados em: Bartoluzzio, \& Anjos. (2019). Replication Data for: "Political Cycles and Fiscal Management in Brazilian Municipalities" published by RAC - Revista de Administração Contemporânea. Published by Journal of Contemporary Administration, 24(2), 2019. [Data set]. Journal of Contemporary Administration (RAC). Mendeley. http://doi.org/10.17632/zg7tvnrkn9.1 